\title{
Experimental Investigation of Heat Transfer Characteristics in Stepped Rectangular Micro- Channels
}

\author{
Shravan Kumar Gulvadi \\ Bachelor student in Mechanical Engineering, The National Institute of Engineering, Mysore
}

\begin{abstract}
Experimental investigation was conducted to explore the heat transfer behaviour of stepped rectangular microchannels in laminar-single phase flow. The classical correlations used for predicting the heat transfer behaviour in single phase flow in rectangular microchannels was extended to predict the same in stepped rectangular microchannels and its applicability was verified. The microchannel considered had a hydraulic diameter of 454 microns. The test piece was made of aluminium and contained ten channels in parallel. Deionized water was used for the experimentation and the Reynolds number was varied from 300 to 1500 . The results indicated considerable concurrence between the experimental results and the Choi correlation for Reynolds numbers less than 800.
\end{abstract}

Keywords: Microchannels, Liquid cooling, Electronic chip cooling, forced convection

\section{Introduction}

The continued miniaturization of electronic systems has resulted in a dramatic increase in the amount of heat generated per unit volume, which jeopardizes the safety and reliability of the system as the failure rate of electronic equipment increases exponentially with temperature. Therefore, thermal management and control has become increasingly important in the design and operation of electronic equipment. Microchannels and minichannels are naturally well suited for this task, as they provide a large heat transfer surface area per unit fluid flow volume. However the understanding of the involved physics in the heat transfer and fluid flow behaviors in such channels has been questioned a number of times. One of many reasons for this includes the inconsistency observed in the predicted and measured heat transfer coefficient and critical Reynolds number. To account for these observed discrepancies reasons such as the inaccuracies and lack of precision involved in micro-fabrication, surface roughness, aspect ratio effects etc have been proposed.

However recent studies have confirmed that the behaviour of microchannels is quite similar to that of conventional channels, The studies of Liu and Garimella [17], Popescu et al. [09], Harms et al. [04] showed that conventional correlations hold good for laminar flows in microchannels for a wide range of hydraulic diameter. In the present paper such conventional correlations are being extended to stepped rectangular channels and their validity is being verified.

Stepped rectangular cross section offers a significant increase in heating perimeter when compared to a rectangular microchannel of same cross sectional area and depth resulting in pronounced heat transfer with minimal added machining complexity.

\section{Nomenclature}

A convection heat transfer area (per channel), $\mathrm{m}^{2}$

$\mathrm{H}_{1}, \mathrm{H}_{2}$ channel heights, $\mathrm{m}$
$\mathrm{C}_{\mathrm{p}} \quad$ specific heat, $\mathrm{kJ} / \mathrm{kg}^{\circ} \mathrm{C}$

$\mathrm{D}_{\mathrm{h}} \quad$ hydraulic diameter, $1 \mathrm{~m}$

h convective heat transfer coefficient, $\mathrm{W} / \mathrm{m}^{2}{ }^{\circ} \mathrm{C}$

$\mathrm{k}$ thermal conductivity, $\mathrm{W} / \mathrm{m}^{\circ} \mathrm{C}$

L channel length

$\mathrm{N}$ number of microchannels

$\mathrm{Nu} \quad$ Nusselt number

Pr Prandtl number

Q heat transfer rate, $\mathrm{W}$

$\dot{m} \quad$ mass flow rate

$\mu \quad$ Dynamic viscosity of the fluid

$\mathrm{V} \quad$ Velocity of the fluid

$\rho \quad$ Fluid density

Re Reynolds Number

$\mathrm{T}_{\text {in }} \quad$ Temperature of the Fluid at inlet to the microchannel

$\mathrm{T}_{\text {out }} \quad$ Temperature of the fluid at the outlet

$\mathrm{T}_{\mathrm{bm}} \quad$ Bulk mean temperature of the fluid

$\mathrm{T}_{\mathrm{wm}} \quad$ Mean wall temperature of the substrate

$\mathrm{W}_{1}, \mathrm{~W}_{2} \quad$ Microchannel width

\section{Fabrication of Microchannels}

The planned cross-sectional profile of the channel is as shown in the fig 2.1 but due to the fabricational limitations of the EDM process the edges were filleted to the radius of the wire used in the machining process.

An Aluminum 64430 block was machined to a final dimension of $210 \times 64 \times 30 \mathrm{~mm}$. Holes for catridge heater and thermal sensors were drilled, pocketing was performed at either ends of the block to function as water reservoirs for the microchannels. The top surface was machined to a finish of one micron, Wire EDM process was carried out on this surface to attain the final profile of the microchannel. In total ten microchannels of the same cross section were machined. A poly-methyl methacrylate plate was fixed on top of this surface to act as a transparent cover. A container box was fabricated out of wood and filled with glass wool to function as an insulating box.

The Experimental setup contained four basic components:

Volume 6 Issue 12, December 2017 


\section{International Journal of Science and Research (IJSR) \\ ISSN (Online): 2319-7064 \\ Index Copernicus Value (2016): 79.57 | Impact Factor (2015): 6.391}

1) The insulated box containing the aluminum block with micro-channels and the glass plate along with the thermocouples and the cartridge heater.

2) A display system to indicate the thermocouple readings.

3) A peristaltic pump.

4) A de-ionised water source and sink.

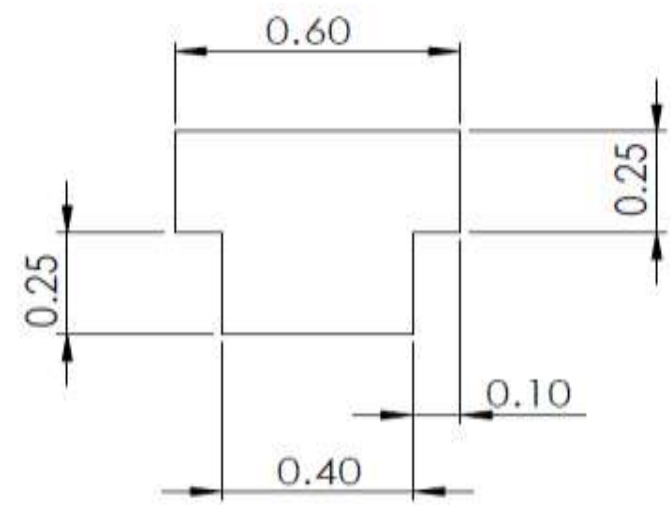

Figure 2.1: Microchannel Profile (Dimensions in mm)

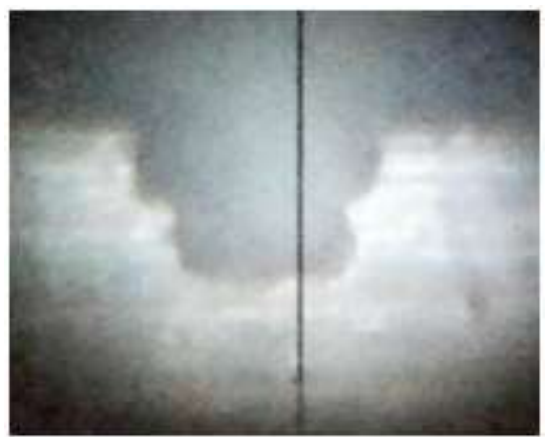

Figure 2.2: Micrograph of stepped rectangular microchannel

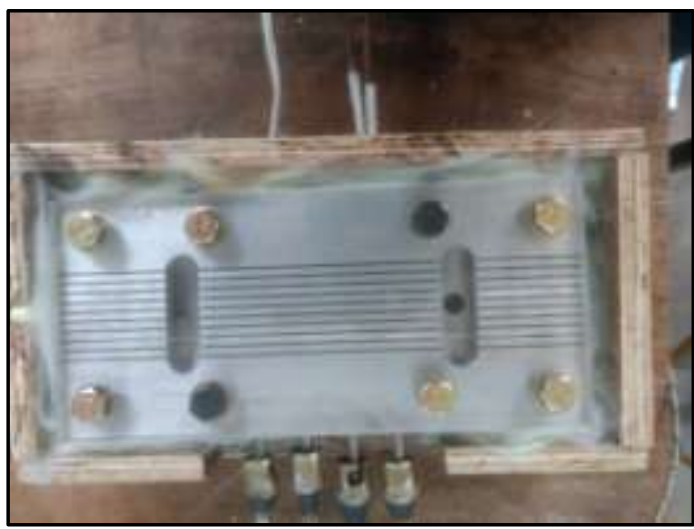

Figure 2.3: Assembled Microchannel Heat sink

\section{Experimental Methodology}

The schematic of the overall setup is as follows,

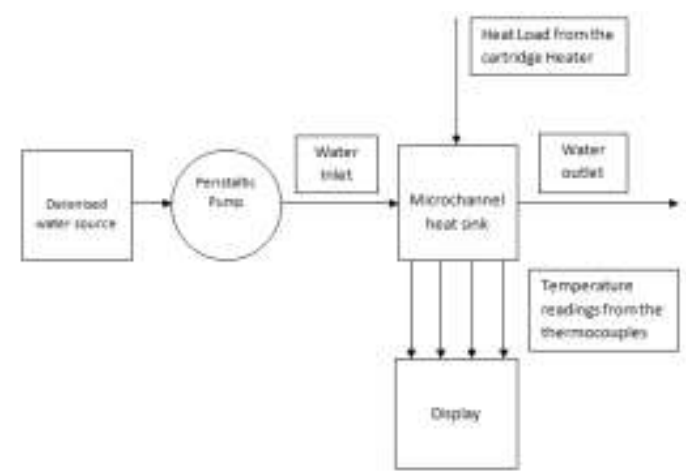

Figure 3.1: Schematic of Experimental setup

Calibrated K- Type thermocouples were used for the measurement of the temperature. They are simple, rugged and inexpensive and can be used for wide range of temperatures. A cylindrical cartridge heater of $100 \mathrm{~W}, 230$ volt was used as the heat source. A peristaltic pump with a flow range of $0.8 \mathrm{l} / \mathrm{hr}$ to $19 \mathrm{l} / \mathrm{hr}$ was used to pump the coolant into the microchannel heat sink. The thermocouples used to measure the temperature along the microchannel were connected to the display panel.

Flow rate corresponding to the required Reynolds number was set in the peristaltic pump. For the calculation of the flow rate the fluid properties corresponding to an assumed bulk mean temperature were used. The actual Reynolds numbers which was attained was then recalculated by substituting the fluid properties at the assumed temperature with the actual bulk mean temperature attained, given by the arithmetic mean of the measured inlet and outlet fluid temperatures.

Temperature readings from the thermocouples were monitored and the readings were noted down once the steady state was attained.

The quantity of heat carried away by the fluid which is always less than the Heat output of the heat source due to inevitable losses is calculated from the difference between the inlet and outlet fluid temperatures.

$$
Q=\dot{m} \cdot C_{p} \cdot\left(T_{\text {in }}-T_{\text {out }}\right)
$$

Heat transfer coefficient is calculated from Newton's law of cooling given by,

Where,

$$
Q=h \cdot A \cdot\left(T_{w m}-T_{b m}\right)
$$

$$
A=2\left(H_{1} \cdot L+H_{2} \cdot L\right)+W_{1} \cdot L
$$

Heat transfer from the top edge of the microchannel is neglected as it's made of PMMA whose thermal conductivity is less than $0.2 \%$ of aluminum.

The Nusselt number is then calculated from its definition,

$$
N u=\frac{h \cdot D_{h}}{k}
$$

This method is repeated for different Reynolds number.

\section{Uncertainty Analysis}

In the present work the experimental data obtained is analyzed in the framework of Conventional theory. The flow

\section{Volume 6 Issue 12, December 2017}




\section{International Journal of Science and Research (IJSR) \\ ISSN (Online): 2319-7064 \\ Index Copernicus Value (2016): 79.57 | Impact Factor (2015): 6.391}

rate was measured to set the required Reynolds number at the beginning of each iteration.

$$
R e=\frac{\rho V D_{h}}{\mu}
$$

The respective uncertainty comes to be,

$$
\frac{\partial R e}{R e}=\left\{\left(\frac{\partial Q}{Q}\right)^{2}+\left(\frac{\partial H}{H}\right)^{2}+\left(\frac{\partial W}{W}\right)^{2}\right\}^{1 / 2}
$$

from manufacturer specification we have $\delta Q= \pm 1.01 \%$ of flow meter reading $\delta \mathrm{H}=\delta \mathrm{W}=10 \mu \mathrm{m}$, considering $\mathrm{H}=\mathrm{H}_{1}+\mathrm{H}_{2}=$ $500 \mu \mathrm{m}$ and $\mathrm{W}=\frac{\mathrm{W} 1+\mathrm{W} 2}{2}=500 \mu \mathrm{m}$, we get,

$$
\frac{\partial R e}{R e}=3 \%
$$

$\delta \mathrm{T}$ for PT100 K-type thermocouple $1 / 3 \mathrm{DIN}$ at $56.8^{\circ} \mathrm{C}$ (Max measured Temp) is $\pm 0.13^{\circ} \mathrm{C}$.

\section{Results and Discussions}

The variation of Nusselt number with Reynolds number is as shown in the fig.5.1

The comparison of Experimental results with different Empirical formulae developed for single phase laminar flow in microchannels by researchers namely, $\mathrm{Wu}$ and Little [2], Choi et al [1], Sieder-Tate [13] is as follows,

As can be seen from the comparison there is considerable agreement between the experimental results and Choi correlation for flows with lower reynolds number. For flows with Reynolds number less than 800 the deviation in predicted Nusselt number is less than $10 \%$. The results show significant deviation for higher Reynolds number. On the contrary considerable agreement is observed between Sieder-tate correlation at higher Reynolds number, for flows with Reynolds number between 900 and 1500 the deviation between experimental results and Sieder-tate correlation is less than $10 \%$.

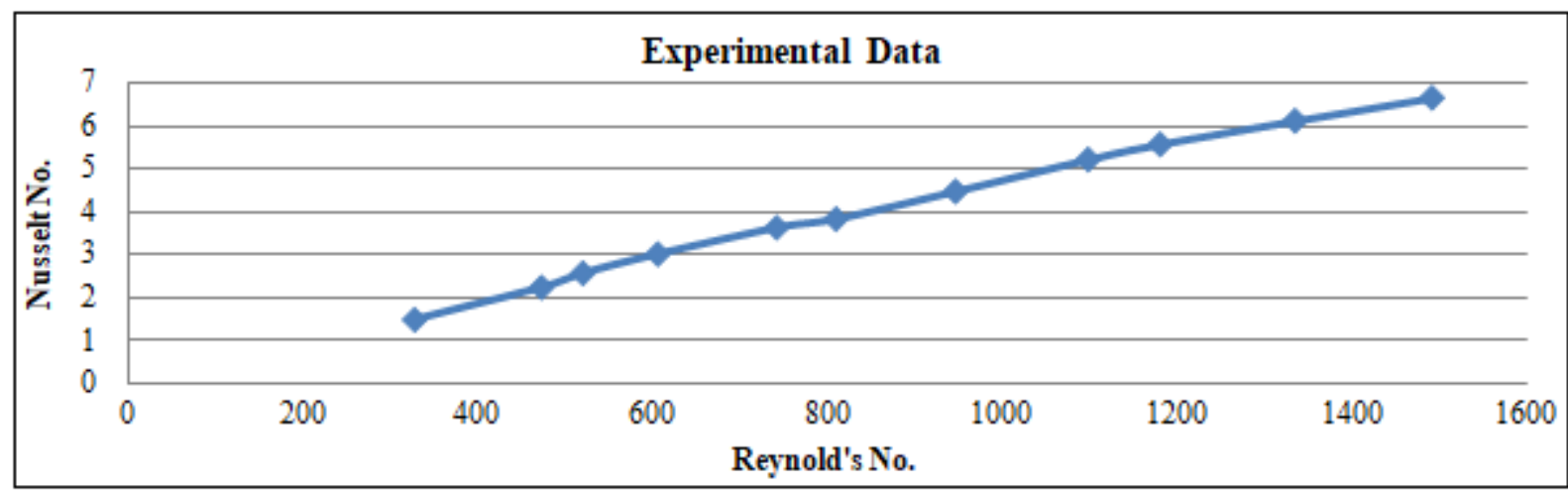

Figure 5.1: Experimental data

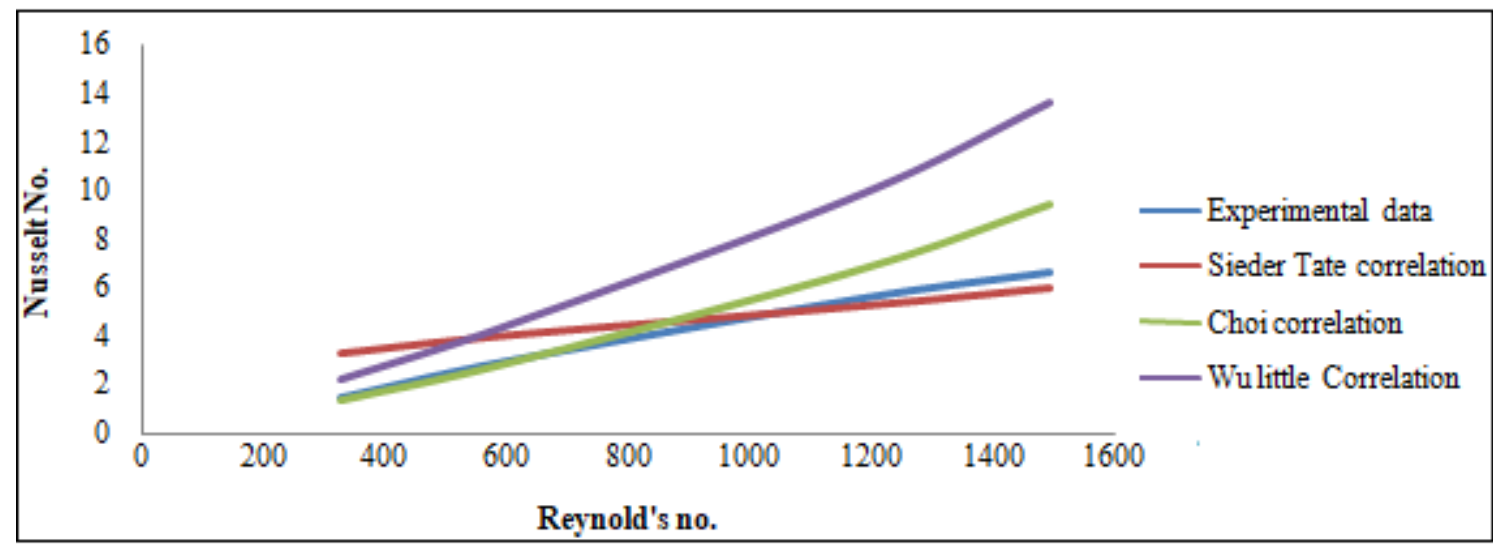

Figure 5.2: comparison of experimental data with conventional correlations

\section{Conclusion}

This paper experimentally studies the heat transfer in stepped rectangular microchannel having a hydraulic diameter of $0.454 \mathrm{~mm}$ in single-phase laminar flow regime and checks the feasibility of conventional correlations from literature.

Considerable agreement was observed between the experimental results and Choi correlation for flows with
Reynolds number $<800$ and with Sieder-tate correlation for flows with $1500>$ Reynolds number $>800$.

Further studies are required to be undertaken to develop a generalized correlation for Nusselt number in stepped rectangular microchannels. More such investigations into novel geometrical cross sections which might result in improved performance of microchannel heat sinks without excessive cost burden also need to be undertaken. 


\section{References}

[1] S.B. Choi, R.F. Barron, R.O. Warrington, Fluid flow and heat transfer in microtubes, Micromech. Sensors Actuat. Syst. ASME DSC 32 (1991) 123-134.

[2] P. Wu, W.A. Little, Measurement of friction factors for the flow of gases in very fine channels used for micro miniature refrigerators, Cryogenics 24 (1983) 273-277.

[3] Single-phase liquid cooled microchannel heat sink for electronic packages by H.Y. Zhang, D. Pinjala, T.N. Wong, K.C. Toh,Y.K. Joshi, 2004.

[4] T.M. Harms, M.J. Kazmierczak, F.M. Gerner, Developing convective heat transfer in deep rectangular microchannels, Int. J. Heat Fluid Flow 20 (1999) 149157.

[5] Fluid flow in micro-channels by G. Hetsroni, A. Mosyak, E. Pogrebnyak, L.P. Yarin,2005.

[6] Analysis of Flow and Thermal Performance of a WaterCooled Transversal Wavy Microchannel by Gongnan Xie, Jian Liu, Weihong Zhang, Bengt Sunden,2012.

[7] Integrated Microchannel Cooling for ThreeDimensional Electronic Circuit Architectures by Jae-Mo Koo, Sungjun Im, Linan Jiang, Kenneth E. Goodson, 2004.

[8] Laminar Forced Convection Heat Transfer in the Combined Entry Region of Non-Circular Ducts by Y. S. Muzychka, M. M. Yovanovich,

[9] A. Popescu, J.R. Welty, D. Pfund, D. Rector, Thermal measurements in rectangular microchannels, in: Proceedings of IMECE2002, IMECE2002-32442, 2002.

[10] Jae-Mo Koo, SungjunIm, LinanJiang, Kenneth E. Goodson Transversal Wavy,2005, Integrated microchannel Cooling 2004.

[11]X.F.Peng, G.P.Peterson 1996, Convective heat transfer and flow friction for water flow in Microchannel structures.

[12] Weilinqu, Issam Mudawar 2001, Experiment and numerical study of pressure drop and heat transfer in a single phase microchannel heat sink.

[13]F.P. Incropera, D.P. DeWitt, Fundamentals of Heat and Mass Transfer, John Wiley and Sons, New York, 1996.

[14] Jundika.C.Kurnial, Agus.P.Sasmito, Arun.S.Mujumdar 2011, Numerical investigation of laminar heat transfer performance of various cooling channel designs.

[15] Mark.E.Stinky, Satish.G.Kandlikar 2006, Single phase liquid friction factors in microchannels.

[16] G.Hetsroni, A.Mosyak, E.Pogrebnyak, L.P.Yarin 2005, Heat ransfer in Microchannels: Comparison of experiments with theory and numerical results. 